This is the author's final, peer-reviewed manuscript as accepted for publication. The publisher-formatted version may be available through the publisher's web site or your institution's library.

\title{
The impact of supply chain analytics on operational performance: a resource-based view
}

Bongsug (Kevin) Chae, David Olson \& Chwen Sheu

\section{How to cite this manuscript}

If you make reference to this version of the manuscript, use the following information:

Chae, B. K., Olson, D., \& Sheu, C. (2014). The impact of supply chain analytics on operational performance: A resource-based view. Retrieved from http://krex.ksu.edu

\section{Published Version Information}

Citation: Chae, B. K., Olson, D., \& Sheu, C. (2014). The impact of supply chain analytics on operational performance: A resource-based view. International Journal of Production Research, 52(16), 4695-4710.

Copyright: (c) 2013 Taylor \& Francis

Digital Object Identifier (DOI): doi:10.1080/00207543.2013.861616

Publisher's Link:

http://www.tandfonline.com/doi/full/10.1080/00207543.2013.861616\#.VFFPecVdVQx

This item was retrieved from the K-State Research Exchange (K-REx), the institutional repository of Kansas State University. K-REx is available at http://krex.ksu.edu 


\section{The Impact of Supply Chain Analytics on Operational Performance: A Resource-Based View}

\section{Introduction}

Firms are under heavy pressure to improve supply chain planning and performance because of factors such as increasing uncertainty and competition. Manufacturers have adopted a variety of innovative technological and process-based solutions to obtain and sustain competitive advantage over their competitors. In supply chain management, there is growing interest in business analytics, which is also called Supply Chain Analytics (SCA). SCA refers to the use of data and quantitative tools and techniques to improve operational performance, often indicated by such metrics as order fulfillment and flexibility, in supply chain management (Handfield 2006, Davis-Sramek et al. 2010, Davenport and O'Dwyer 2011, O'Dwyer and Renner 2011). There are numerous cases of successful SCA implementation by leading firms. For example, Proctor \& Gamble and Walmart are reported to have significantly improved operational efficiency through the use of data and analytical IT tools for supply chain decisions (Davenport and Harris 2007, Davenport and O'Dwyer 2011, O'Dwyer and Renner 2011, SAS 2012). Tesco, one of the world's largest retailers, based in the UK, has experienced significant cost savings through SCA over the years (Clark 2013).

Analytics in SCM is not necessarily a new idea (Davenport and O'Dwyer 2011), since various quantitative techniques and modeling methods have long been used in manufacturing firms (Turban and Sepehri 1986, Shapiro 2000, Kusiak 2006, Trkman et al. 2010). The recent surge of interest in SCA is accompanied by new challenges and opportunities in both business and information technology (IT) environments. These challenges include issues arising from managing large amounts of data (e.g., data availability, data quality) and dealing with 
environmental uncertainties (Handfield and Nichols 2004, Liberatore and Luo 2010, Huner et al. 2011, Lavalle et al. 2011, Manyika et al. 2011).

First, IT-based innovations have generated and captured "more data while also changing the nature of businesses” (Kohli and Grover 2008, p. 32). For instance, a leading consumer goods firm (Li \& Fung) reported the flow of over 100 gigabytes of data through the firm’s supply chain network on a given day in 2009 (Economist 2010). The opportunity to gain competitive advantage may thus arise from how firms manage data (Vosburg and Kumar 2001, Forslund and Jonsson 2007, Oliva and Watson 2011). Another major challenge for businesses is the increasing uncertainty in both demand (e.g., consumer market) and supply sides of their businesses. Dealing with demand and supply uncertainty by means of proper supply chain planning has been a major theme in many recent SCM studies (Oliva and Watson 2011, Demirkan and Delen 2012).

In response to those challenges, SCA has been proposed as a promising approach to better manage data, utilize IT resources, and prepare for effective supply chain planning (Handfield 2006, Davenport et al. 2010, Davis-Sramek et al. 2010, Viswanathan and Sadlovska 2010). This new generation of analytic tools can develop a firm’s IT and data management capabilities to enhance planning and improve operational performance (Kohli and Grover 2008, Shapiro 2010, Mithas et al. 2011). It is suggested that firms can use SCA from data acquisition (e.g., RFID) and repository (e.g., ERP) technologies to improve supply chain planning through IT-enabled planning and scheduling systems (Davenport and O'Dwyer 2011, O'Dwyer and Renner 2011). To date, however, there has been very limited empirical research in this datadriven innovative approach to SCM. 
SCA research is in its early stage and there is a general lack of theory and of empirical studies. Using the resource-based view (RBV) as the theoretical base, this study expands the understanding of components and performance of SCA. The principal idea of the RBV is that the competitive advantage of a firm lies in its heterogeneous resources, which are valuable, inimitable, and non-substitutable (Barney 1991). (Please see Armstrong and Shimzu (2007) and Newbert (2007) for a more comprehensive review of empirical research using RBV). Accordingly, we develop a theoretical perspective on SCA as a valuable, inimitable, and nonsubstitutable resource in manufacturing contexts that can be a source of sustained competitive advantage. SCA is a combination of three sets of data and IT-enabled SCM resources, which we refer to as data management resources (DMR), IT-based supply chain planning resources (IPR), and performance management resources (PMR) (Figure 1). Manufacturing firms acquire and use various IT and organizational resources in these three aspects of SCA. Firms use diverse analytical and IT resources for acquiring, storing, and retrieving data. DMR includes IT-related resources (e.g., RFID, ERP) and analytical capabilities (e.g., mathematical optimization techniques) for data acquisition and management. Also, different software tools (or IPR), from less sophisticated to more advanced, are used for supply chain planning in manufacturers. IPR represents these IT resources (e.g., advanced planning systems) embedding various optimization and predictive analytics (e.g., mathematical programming, statistical analysis). Manufacturers put different degrees of investment in the use of data-oriented process and performance improvement methodologies such as statistical process control and Six Sigma, which are considered PMR.

$<$ Figure 1 here $>$ 
In this study, these three sets of analytics and IT resources are viewed as complementary, enabling each other. This perspective is developed with reference to the RBV theory, which acknowledges that resources are important for competitive advantage and, in particular, ITrelated resources become more effective when combined with non-IT-related resources as complementarities. This study tests hypotheses exploring the relationships among those three dimensions of SCA and the link between SCA and user satisfaction of supply chain planning and SCM performance (e.g., reliability, flexibility). A major contribution of this study is that it offers empirical findings on the relatively new topic of businesses' use of supply chain analytics.

Particularly, the study's findings shed light on the importance of three sets of complementary ITenabled resources for successfully taking advantage of business analytics for SCM, the significant role of data management resources as the key building block of SCA, and the positive impact of SCA on operational performance.

Section 2 reviews relevant literature pertaining to supply chain analytics. Three types of IT and organizational resources are introduced from the RBV perspective. In Section 3, the research model is developed with the hypotheses of the relationships among types of resources and performance variables. The research methodology, including samples and measurements, is discussed in Section 4, followed by the presentation of statistical results in Section 5. Section 6 discusses results, and Section 7 concludes with managerial implications, research limitations, and suggestions for future research.

\section{Theoretical Background}

\subsection{Resource-based view}

The resource-based view (RBV) holds that resources vary across firms, and differences in resource levels that persist over time enable firms to sustain competitive advantage (Penrose 
1959, Wernerfelt 1984, Barney 1991). Under RBV, various technological and organizational practices can be considered resources for acquiring sustained competitive advantage. For instance, organizational knowledge, managerial skills, backend integration, technology, and manufacturing facilities are viewed as manufacturer resources (Dong et al. 2009). Also, diverse SCM-related activities and practices (e.g., supply management practices, environmental management practices) are considered important resources for improving operational performance (Narasimhan and Schoenherr 2012, Blome et al. 2013).

IT is often viewed as a firm resource in the RBV framework (Barney 1991, Wade and Hulland 2004) to create sustained competitive advantage (Barney 1991). Recent studies have studied the role of other resources as complementarities in the effects of IT on firm performance (Powell and Dent-Micallef 1997, Tippins and Sohi 2003, Wade and Hulland 2004, Jeffers et al. 2008, Kohli and Grover 2008). Specifically, IT becomes an effective firm resource when it is complemented by other resources or practices (Powell and Dent-Micallef 1997, Tippins and Sohi 2003, Nevo and Wade 2010). Kohli and Grover (2008, p. 26) argued that "IT, as simply hardware and software tools, does not create value in isolation, but must be a part of a business value creating process with 'other' IT and organizational factors operating in a synergistic manner”. These “other” IT and organizational factors are called complementarities. The interaction of IT and complementarities would lead to competitive advantage (Wade and Hulland 2004).

\subsection{Supply chain analytics (SCA)}

The emergence of new terms, such as SCA, reflects a broad interest in leveraging the business value of supply chain data and harnessing the power of various analytical technologies and methods. Top performing companies are better at utilizing their data for business planning 
and execution (Kiron et al. 2011, Lavalle et al. 2011) and this has led to the increase in supply chain integration and visibility (Viswanathan and Sadlovska 2010, O'Dwyer and Renner 2011). In general, academic research expects the benefits of analytics in supporting supply chain operations (Trkman et al. 2010, Davenport and O'Dwyer 2011).

Manufacturers have used statistical modeling and optimization (Turban and Sepehri 1986, Shapiro 2000, Chellappa et al. 2010, Davenport and O'Dwyer 2011) to help deal with supply chain problems (e.g., inventory optimization) on an ad-hoc basis. However, the role that SCA plays, regarding both supply and demand factors, is growing in importance and deserves

more thorough investigation. Demand factors include the massive amount of data generated from manufacturing activities and customer and supplier interaction, growing competition and uncertainty, and the need for enterprise-level planning on a daily or regular basis. Supply factors include powerful IT for data management and supply chain planning and advanced data-driven techniques for better process and quality control.

\subsection{A RBV of SCA}

In this study, firm resources (e.g., IT) as a source of sustained competitive advantage are used to conceptualize SCA, to test the relationships between different SCA-related resources, and to predict their impact on supply chain planning satisfaction and operational performance. Theoretically, IT-enabled resource is an RBV-based construct and is supplemented with concepts from systems theory (Nevo and Wade 2010, Nevo and Wade 2011). The concept, defined as “a system (or a subsystem, depending on one's perspective) comprised of an IT asset and an organizational resource (OR) in a relationship” (Nevo and Wade 2011, p. 405), postulates IT assets as a potential resource for competitive advantage. This conceptual framework asserts 
that such potential can be realized when IT is integrated with other resources (Nevo and Wade 2010).

Analytics, in general, does not refer to a particular technology, method, or practice (Davenport et al. 2010, Trkman et al. 2010, Turban et al. 2011). Rather, it is a combination of multiple IT-enabled resources, which includes both IT assets and organizational resources, helping the use of “data, analytical IT, and fact-based management methodologies” (Davenport and Harris 2007) in decision making. Therefore, SCA is viewed as a combination of IT-enabled resources for manufacturing-related data management, supply chain planning, and data-driven process and quality improvement. It is a data-driven, analytical decision making approach to SCM supported by IT resources for data management, supply chain planning and evidence-based management methodologies. These IT-enabled resources would include enterprise IT infrastructure (e.g., ERP, RFID) and analytical methods for data management, technologies embedding optimization and predictive analytics (e.g., mathematical programming) for supply chain planning, and data-driven supply chain organizational resources (e.g., statistical process control, Six Sigma) for improving manufacturing processes and performance. We give general definitions of three types of SCA IT-enabled resources:

- Data management resources (DMR): Data has long been recognized as a critical asset for organizations (Marchand et al. 2000). The information processing view asserts that "the greater the uncertainty of the task, the greater the amount of information that has to be processed between decision makers during task execution in order to achieve a given level of performance” (Galbraith 1974, p. 28). Thus, data management becomes critical for firm performance and IT serves as the infrastructure for data capture, manipulation, and redistribution (Fairbank et al. 2006). DMR represents the firm’s IT resources for such 
activities as data acquisition, storage, and retrieval. For example, ERP is an IT resource and serves as an integrated, single-instance database for efficient data management providing integrated data for manufacturing planning and control (Su and Yang 2010). Analytic techniques and methods can also be used to generate important manufacturing data or master data (e.g., lead time, batch size). Data management is an important dimension in the quality/process management literature (Flynn et al. 1994, Nair 2006, Kaynak and Hartley 2008).

- IT-based supply chain planning resources (IPR): IPR represents the IT resources embedding various optimization and predictive analytics, such as mathematical programming, simulation, statistical analysis and machine learning algorithms. These analytic techniques and methods are invaluable means for supply chain planning activities, such as master production planning, material requirements planning, and capacity planning (Kreipl and Pinedo 2004, Stadtler 2005, Vollmann et al. 2005, Hendricks et al. 2007). Supply chain planning software (e.g., Advanced Planning Scheduling) embed these analytics and also have the capability of accessing large data stores (Dehning et al. 2007). DMR is important for IPR since the data become inputs for supply chain planning. In general, the more sophisticated those technologies are, the more such analytic methods and data access capabilities are embedded (Singh 2003).

- Performance management resources (PMR): While IPR is primarily used for supply chain planning; our use of PMR refers to the firm's resources focusing on closing the gap between planning and execution, through monitoring and correcting manufacturing processes and performance. This is another key area where analytical methods (and technologies) can have positive impacts (Houghton et al. 2004, Yang et al. 2007, Turban et al. 2011). PMR enables 
analytical thinking and fact-based management. These resources are data-driven SCM practices (Kannan and Tan 2005), often combined with performance metrics (Schroeder 2008), data visualization of quality problems (Zu et al. 2008), and analytical methods (Scheuermann et al. 1997). PMR becomes an integral component for SCA, since these organizational resources help monitor supply chain execution, control performance variability, and improve the quality of planning and execution. These resources have been extensively surveyed in the literature (Rungtusanatham 2001, Shah and Ward 2003, Holweg 2007, Shah and Ward 2007, Schroeder 2008, Zu et al. 2008), but with no focus on their dataoriented, analytical aspects.

In summary, these three types of IT and organizational resources are related and synergistically affect supply chain planning, as well as SCM operational performance. In particular, DMR is expected to serve as the foundation of SCA, since IPR and PMR rely on data as inputs. Advanced IT resources for data management can enable the use of comprehensive and reliable data by IPR and PMR. However, these IT-enabled resources are complementary; DMR, IPR, and PMR are not expected to drive performance individually, but, rather, they need to work together.

\section{Research Model \& Hypotheses}

When SCA is viewed as a combination of IT-enabled resources, we expect there will be interactions among those elements (data management resources, IT-based supply chain planning resources, and performance management resources). Thus, we first consider three internal relationships: (H1) data management resources are positively associated with IT-based supply chain planning resources; (H2) data management resources are positively associated with 
performance management resources; (H3) IT-based supply chain planning resources are positively associated with performance management resources.

Then, with two outcome latent variables_-supply chain planning satisfaction and SCM operational performance-we explore the impact of SCA: (H4a) data management resources are positively associated with supply chain planning satisfaction; (H4b) IT-based supply chain planning resources are positively associated with supply chain planning satisfaction; (H4c) performance management resources are positively associated with supply chain planning satisfaction; (H5a) supply chain planning satisfaction are positively associated with SCM operational performance; (H5b) performance management resources are positively associated with SCM operational performance. These hypotheses are presented in Figure 2. The remainder of this section provides the theoretical development of the research hypotheses.

$<$ Figure 2 here $>$

\subsection{Linking IT-enabled resources of SCA}

Manufacturing firms have different levels of IT-enabled resources for data management. Some firms possess advanced IT-enabled resources for data management, such as ERP and RFID, that can enable automatic data acquisition, high accuracy in manufacturing-related data quality, and easy data retrieval and use for SCM planning and control. For example, RFID offers many benefits to supply chain management (Sellitto et al. 2007) and a major benefit is data acquisition capability (Singh 2003, Delen et al. 2007). ERP is widely adopted as a centralized data repository (Bendoly 2003, Olson et al. 2013). Some firms also use sophisticated mathematical models or analytical techniques to determine manufacturing-related master data (e.g., lead time). 
IPR (IT-based supply chain planning resources) involves processing a large volume of production, sales, delivery, and material data for effective planning and scheduling (Gustavsson and Wanstrom 2009, Dionne and Kempf 2011). A centralized corporate repository allows the same data to be used for all types of planning and helps such planning to correctly reflect the company's condition (Hendricks et al. 2007). Effective supply chain planning relies on "informational" efficiency, meaning that data is collected, aggregated, and distributed for the planning process (Oliva and Watson 2011). Performance management practices or resources (PMR), such as quality management and Six Sigma, rely on manufacturers' planning and execution data (Kannan and Tan 2005, Zu et al. 2008). In other words, DMR (data management resources) can be a key contributor to PMR.

As argued by Davenport et al. (2010, p. 23): You can’t be analytical without data. Data are the basis for both supply chain planning and performance management. Supply chain planning relies on the availability of financial and operational data (Shapiro 2010, Oliva and Watson 2011). Thus, data management resources are strongly required prior to IT-based supply chain resources (IPR). For example, IT-based resources for inventory control need to extract data from data management resources such as ERP (Stadtler 2005, Vollmann et al. 2005). Also, measuring and improving performance of quality and processes is not possible without access to properly managed data. Thus, quality data and reporting are important for and strongly associated with performance management (Kaynak and Hartley 2008, Mithas et al. 2011). Accordingly, we expect that DMR influences the adoptions of IPR and PMR: the adoption of advanced IPR and diverse PMR presupposes the existence of sophisticated DMR.

H1. Data management resources (DMR) positively affect IT-enabled supply chain planning resources (IPR) 
H2. Data management resources (DMR) positively affect performance management resources (PMR)

Manufacturers differ considerably in terms of their analytical capabilities used for supply chain planning activities, such as material planning, inventory control and shop floor control. Some manufacturers possess advanced planning technologies, embedding optimization algorithms, data mining tools, and so on. These analytics-embedded IT sources offer several benefits, including reducing planning errors and potential disruption and increasing planning accuracy (Hendricks et al. 2007). While IPR might potentially lead to positive SCM outcomes, such as improved on-time delivery (Wu et al. 2006), and financial outcomes, such as profitability (Hendricks et al. 2007), in the RBV of IT (Devaraj and Kohli 2003, Wade and Hulland 2004, Kohli and Grover 2008, Nevo and Wade 2010), their value is expected to be attained through complementary resources, PMR.

IPR in general increases visibility and coordination in manufacturing planning and control (Vollmann et al. 2005). This stimulates firms to engage in sensing potential gaps between planning and execution and correcting errors in different areas. For example, IT-based planning reveals forecasting errors, overstocks, and other issues, which require coordination to fix. As a result, IPR is expected to increase the need for performance management. Firms are likely to increase relevant resources for performance management. Among previous studies, MartinezLorente et al. (2004) suggested that IT resources are positively associated with supply chain practices, such as TQM. Thus, we posit that

H3. IT-enabled supply chain planning resources (IPR) positively affect performance management resources (PMR).

\subsection{Relationships with outcome constructs}


The impact of SCA on firm-level outcomes may be the result of both indirect and direct influences. The resource-based view (RBV) of SCA indicates that DMR and IPR are more technological than organizational, while the opposite is true for PMR. Many RBV-based studies suggest that the impact of IT on performance is likely to be indirect, through non-IT factors or resources as complementary resources (Bharadwaj 2000, Wade and Hulland 2004, Devaraj et al. 2007, Jeffers et al. 2008, Nevo and Wade 2010). Therefore, we consider "supply chain planning satisfaction (SAT)" as an indicator for planning quality. Satisfaction is the level of favorable “attitude” (DeLone and McLean 1992, Wixom and Todd 2005) toward supply chain planning. SAT is the measure for the perceived quality or performance of supply chain planning activities.

Accordingly, we expect that each component of SCA positively influences supply chain planning satisfaction. IT resources, such as advanced data repository technology and supply chain planning software, are likely to influence the attitude toward supply chain planning. The literature shows that the quality of data and IT positively influences satisfaction, which in turn results in positive organizational impacts or benefits (DeLone and McLean 1992, Wixom and Todd 2005, Petter and McLean 2009). In addition to DMC and IPR, process and performance management is important to the outcome of supply chain planning. The planning process is influential in supply chain planning performance (De Snoo et al. 2011). The implementation of data-driven performance practices has positive effects on planning quality, which in turn leads to operational improvement (de Leeuw and van den Berg 2011). As a result, we expect that DMR, IPR, and PMR have positive impacts on supply chain planning satisfaction.

H4a. Data management resources (DMR) positively affect supply chain planning satisfaction (SAT)

H4b. IT-enabled supply chain planning resources (IPR) positively affect supply chain planning satisfaction (SAT) 
H4c. Performance management resources (PMR) positively affect supply chain planning satisfaction (SAT)

Finally, we expect that supply chain planning satisfaction and PMR positively affect SCM operational performance. DMR and IPR are mostly associated with the usage of information technology, and this leads us to consider their indirect impact on SCM performance. On the other hand, PMR represents more the data-driven, analytical SCM practices or methodologies for improving SCM performance. Therefore, we expect a direct impact of PMR on SCM performance. For instance, studies show that the investment in quality and process improvement practices has positive effects on organizational or supply chain performance (Merino-díaz De Cerio 2003). In addition, the literature suggests that satisfaction is linked with positive performance impacts on organizational benefits (DeLone and McLean 1992, Petter and McLean 2009).

H5a. Supply chain planning satisfaction (SAT) positively affects SCM operational performance (SCP)

H5b. Performance management resources (PMR) positively affect SCM operational performance (SCP)

\section{Methodology}

\subsection{Data collection}

The research data used in this paper were gathered by the Global Manufacturing Research Group (GMRG), an organization of international academic researchers studying the effectiveness of manufacturing practices in the supply chain worldwide (www.gmrg.org). The GMRG developed its database using a common survey instrument for all countries. Standardized survey instruments are administered by the GMRG members in their respective countries. 
Rigorous translating and back-translating rounds were performed by multiple academics to ensure the equivalency, validity and reliability of the questionnaire versions across different languages (Whybark et al. 2009). The survey questionnaire was previously validated in many studies published in Journal of Operations Management, International Journal of Production Research, Decision Sciences, among others (Schoenherr 2010, Schoenherr and Narasimhan 2012, Yang et al. 2012).

This study uses the data from the GMRG Round 4.0 Survey, which was conducted between 2007 and 2009 (Whybark et al. 2009). The manufacturing site or plant formed the unit of analysis, and a total of 537 samples from 15 countries were used in this study (See Appendix A for distribution statistics). The questionnaire was completed by the operations or manufacturing director of the company. Since a single informant from each of the manufacturing firm was asked to complete the survey, concerns of common method variance (CMV) were addressed by Harmon's single factor test (Podsakoff et al. 2003). The un-rotated factor analysis result shows that no single factor accounts for most of the variance and the first factor captures only 33\% of the variance, which suggests absence of the CMV problem.

\subsection{Measurement of constructs}

The research model includes constructs related to data management resources (DMR), IT-based supply chain planning resources (IPR), performance management resources (PMR), satisfaction on supply chain plans (SAT), and SCM operational performance (SCP). The scales of these five constructs and descriptive statistics are displayed in Appendix B.

Data management resources (DMR) are measured by the level of manufacturers' IT and analytics resources available for three key interrelated aspects of data management: data acquisition, data repository, and master data determination. First, there are multiple methods of 
data acquisition ranging from manual to automatic. RFID is one example of automatic data acquisition in the supply chain. The level of data acquisition resources is measured by how supply chain data, such as inventory transactions and production order status, are acquired. Second, ERP is considered the IT infrastructure for data repository in the corporate world (Bendoly 2003). Therefore, the level of data repository resource is measured by the extent of the manufacturers' investment (money, time and/or people) in ERP. Finally, the level of resources for determining master data is measured by the primary method of determining manufacturing batch sizes, which is an important manufacturing master data.

Supply chain planning involves an array of activities, to include materials, capacity, resources, shop floor operations, and so forth (Vollmann et al. 2005). IT-based supply chain planning resources (IPR) measure the degree of sophistication of IT resources used for various supply chain planning activities. Specifically, this is captured by the type of primary IT resource (e.g., manual system, custom system, commercial system) used for five types of planning: material planning, inventory control, labor planning, shop floor control, and cost planning.

Performance management resources (PMR) measure how extensively the manufacturers' use of data-driven performance management practices impacts quality and process improvement. Examples of these practices include statistical process control, total quality management, and Six Sigma. In this study, PMR is measured by the extent of resources invested in three such practices: statistical process control, total quality management, and Six Sigma.

The literature shows domain specific satisfaction, such as supplier satisfaction (Benton and Maloni 2005) and customer satisfaction (Acar et al. 2010). Supply chain planning satisfaction (SAT) measures the perceived quality or performance of supply chain planning. Satisfaction can refer to either the satisfaction with specific areas or an overall satisfaction, and 
could be either a single-item or a multi-item measure (DeLone and McLean 1992). The survey includes five questions about satisfaction with material planning, inventory control, labor planning, shop floor control, and cost planning.

Finally, supply chain performance (SCP) measures the manufacturers' operational performance. Manufacturers focus on different competitive priorities (Ward et al. 2007) and there are diverse measurements for operational performance (Vollmann et al. 2005). This study uses five operational performance measurements: order fulfillment, delivery as promised, delivery flexibility, flexibility to change output volume, and flexibility to change product mix.

\section{Analysis of the Model}

Our research model is designed to investigate a relatively new subject in SCM research and practice. There is a general lack of theory and few empirical studies on the topic of SCA. Therefore, the research model is exploratory rather than confirmatory, and the objective is theory building and prediction of construct relationships. This makes Partial Least Squares-Structural Equation Modeling (PLS-SEM) suitable for the analysis of the research model (Gefen et al. 2000, Gefen et al. 2011, Hair et al. 2011). The PLS-SEM model reports a two-step process: evaluation of measurements and evaluation of the model (Chin 2010, Hair et al. 2011, MacKenzie et al. 2011). We used industry type and company size as control variables in this analysis. WarpPLS software was used in this PLS analysis for the evaluation of measurement and model.

\subsection{Measurement evaluation}

The evaluation of measurement involved two tests: reliability and validity at the individual indicator level and at the construct level. Composite reliability value is a suitable measure of construct reliability for PLS (Hair et al. 2012). The composite reliability coefficients 
of all five constructs (Table 1) are greater than 0.70 , which has been deemed acceptable in prior studies (Fornell and Larcker 1981, Nunnally and Bernstein 1994). Thus, there is strong consistency of construct measurement. Next, combined loadings were examined to access individual indicator reliability (Hair et al. 2011). Loadings for all the indicators were greater than or at the level of 0.70 (Table 2).

Tables $1 \& 2$ here

We evaluated the discriminant validity of each construct using two procedures. First, the square root of the average variance extracted (AVE), of each construct, was greater than the construct’s squared correlations with other constructs (Fornell and Larcker 1981). Each indicator's loadings were higher than their cross loadings (Chin 2010, Hair et al. 2011). Finally, convergent validity was accessed by evaluating the AVE. The AVE values of all the constructs are greater than or at the level of 0.50 (Table 1 ).

\subsection{Evaluation of the PLS model}

The results from evaluation of the PLS model are reported in Figure 3 and Table 3. The result in Figure 3 strongly supports Hypothesis 1 (DMR $\rightarrow$ IPR). The path coefficient is 0.45 , which is statistically significant at the level of 0.01 . This supports the hypothesis that data management resources, such as data repositories and analytics-based master data management, are associated with the degree of sophistication in supply chain planning technologies adopted by manufacturers. Hypothesis 2 is also supported. The coefficient is 0.42 , which is statistically significant at the level of 0.01 . This suggests that manufacturers' data management resources positively affect the use of performance management resources. We have also tested the relationships in the other direction (IPR $\rightarrow$ MR and PMR $\rightarrow$ DMR). The coefficients for IPR $\rightarrow$ DMR and PMR $\rightarrow$ DMR are found to be 0.34 and 0.36 respectively, which are lower than the 
relationships proposed our original hypotheses (H1: 0.45 and H2: 0.42). In addition, the Rsquared 0.175 is lower than that of the original model, 0.181 .

Figure 3, Table 3 here

Hypothesis 3 is supported. However, it is noted that the coefficient, even though it is statistically significant, is relatively weak compared to those of Hypotheses 1 and 2 . The three types of IT-enabled resources are positively associated. DMR (data management resources), an exogenous latent variable in this research model, is shown to positively influence IPR (IT-based supply chain planning resources) and PMR (performance management resources).

In terms of the impact of SCA on supply chain planning satisfaction, the result supports all three hypotheses (4a; 4b; 4c). This suggests that SCA is likely to enhance supply chain planning satisfaction. Hypothesis 5a, that supply chain planning satisfaction positively affects SCM operational performance, is also supported. The coefficient is 0.15 , which is statistically significant at 0.01 . Finally, the result also supports Hypothesis 5b, which explores the role of PMR as complementarities for DMR and IPR: PMR can increase SCM operational performance. Thus, it is suggested that supply chain analytics can positively influence supply chain planning and SCM operational performance, regardless of industry type and company size.

\section{Discussion and Implications}

Drawing from the resource-based view (RBV), this research has explored the relatively new topic of business analytics for supply chain management, representing the data-driven, analytical decision making approach to SCM. In particular, we have developed an RVB-based theoretical perspective on SCA as a combination of three sets of IT-enabled resources: data management, IT-based supply chain planning, and performance management. We posited that these SCA IT-enabled resources complement one another. According to the RBV literature 
(Bharadwaj 2000, Wade and Hulland 2004, Devaraj et al. 2007, Jeffers et al. 2008, Nevo and Wade 2010), it has been proposed that more technological resources, such as DMR (data management resources) and IPR (IT-based supply chain planning resources), positively affect SCM performance through more organizational resources (PMR) as complementarities. The overall results support these claims and also indicate the positive impact of SCA IT-enabled resources on SCM performance.

\subsection{Relationship between DMR, IPR, and PMR}

The statistical results support the proposition that data management is critical for the manufacturer in deploying SCA. We find that data management resources play an important role in supporting IT-based supply chain planning resources and performance management resources. This implies that manufacturers with high data management resources are likely to be using advanced planning resources and more performance management resources.

These findings shed light on the importance of firms’ data management resources for SCM activities and performance. Few studies have empirically examined the impact of data management resources on SCM. In this sense, data management resources should be considered a key building block of manufacturers’ business analytics initiatives for supply chains. Data has great potential to be transformed to create business value for manufacturers (Marchand et al. 2000, Chae et al. 2005, Davenport et al. 2010, Lavalle et al. 2011, Mithas et al. 2011). It appears that the value of data is transmitted to outcome values through increasing supply chain planning and performance management capabilities. The investment and effort of acquiring data management resources is definitely worthwhile for manufacturers.

The operations management literature has explored the role of analytical information technologies and mathematical modeling methods for supply chain planning (Shapiro 2000, 
Stadtler 2005, Vollmann et al. 2005, Trkman et al. 2010, Oliva and Watson 2011). We have viewed these IT-enabled resources as one of the integral components of SCA. Our results support the supposition that these planning resources are largely dependent upon data resources (DMR $\rightarrow$ IPR): manufacturers with high DMR (data management resources) tend to have sophisticated planning resources. The SCM and IT literature has assumed this large role of data management for supply chain planning technologies. Our findings confirm that the deployment of advanced IPR is likely after the acquisition of DMR.

We also find that IPR (IT-based supply chain planning resources) positively affects PMR (performance management resources). This implies that manufacturers with sophisticated planning technologies would be better able to take advantage of data-driven process and quality and process improvement practices, such as Six Sigma and statistical process control, than those with primitive planning technologies. However, the coefficient of DMR $\rightarrow$ PMR (0.43) is found to be much stronger than that of IPR $\rightarrow$ PMR (0.11). Similar to the findings from the literature on quality improvement (Laframboise and Reyes 2005, Zu et al. 2008) and information management (Mithas et al. 2011), DMR is shown to be a stronger predictor of the degree of performance management resources than IPR.

In summary, our resource-based view of SCA has introduced three types of resourcesDMR, IPR and PMR — and proposed relationships among them. The results indicate that those resources are distinct, yet related, as proposed. In other words, a manufacturer's data management capability would be a good indicator of the level of its IT-based supply chain planning and performance management capabilities. In addition, IT-based planning capability can predict the level of performance management capability. It is evident that firms invest in DMR with the expectation of quality and comprehensive data, which are the necessary input to 
IPR and PMR in practice. This leads to increases in IPR and PMR. Furthermore, more IT-based analytical planning opens the needs and opportunities for data-driven process and quality improvement. Thus, both theoretical discussion and practical application of business analytics for supply chain should consider those three types of resources as a whole for SCA, rather than treating them as separate entities.

\subsection{Relationship between SCA IPR, SAT, and SCP}

There is empirical support that SCA positively impacts outcome variables: supply chain planning satisfaction (SAT) and SCM performance (SCP). We find that all three sets of ITenabled resources (DMR, IPR, PMR) have a positive impact on supply chain planning satisfaction (SAT). Furthermore, SAT positively affects SCP (SCM operational performance). Apparently, these SCA resources are helpful for improving planning quality, which is positively associated with operational performance.

On the other hand, the correlation of DMR and IPR with SCP is found to be statistically insignificant (Table 4). This implies that IT-enabled resources for data management and supply chain planning are important, but do not seem to create business value themselves. Instead, DMR and IPR, which are more technological resources for SCA, have an indirect impact on SCM performance through complementary resources, PMR. This finding suggests at least two important implications.

Table 4 here

First, the RBV-based perspective on SCA, as a combination of three types of data-driven and analytical IT and organizational resources, offers a more theoretically suitable view than what would be a popular, technological view focusing on either data management capability or supply chain planning capability. Without this integrative view, different (potentially incomplete 
or even wrong) conclusions can be reached: for example, an investment in analytical resources for planning alone has led to improving operational performance.

Next, data-driven organizational practices (e.g., statistical process control, Six Sigma), which aim to close the gap between planning and execution through process and quality improvement (Houghton et al. 2004, Yang et al. 2007), are critical, in that they are complementary to technological SCA resources (DMR, IPR) and they have a direct impact on SCM performance. This aligns with the increasingly common perspective on IT value from RBV (Tippins and Sohi 2003, Kohli and Grover 2008, Nevo and Wade 2010). As noted earlier, IT resources for data management (and analytical planning) are critical for SCA. However, it can be claimed, from the RBV of SCA, that those IT resources can be effective only when they are combined with data-driven organizational practices. This interaction of IT and organizational resources leads to performance improvement.

\section{Conclusion: Managerial Implications and Future Research}

The extensive use of supply chain analytics is a relatively new innovation in SCM practice. This research has been exploratory and theory building. While there is growing interest in SCA (Shapiro 2010, Davenport and O'Dwyer 2011, Jander 2011, O'Dwyer and Renner 2011), there is a lack of theory or theoretical framework to study SCA and its impact on SCM performance. This led us to develop a theoretical framework for SCA and identify relevant latent variables and indicators for empirical research.

The results from this exploratory research have several implications for practice. First, there is much discussion among academics and practitioners about the use of business analytics for supply chain management, and the opportunities and challenges this new SCM innovation offers. Anecdotal evidence holds that the use of business analytics is positively associated with 
organizational performance. The important question is whether the use of analytics for supply chain management is just hype or if it has a real effect in enabling performance improvement. Our research indicates that the positive impact of analytics on supply chain performance could be real.

The perspective on analytics for supply chain management (or SCA) in this research goes beyond a single technology (e.g., APS, ERP) or methodology (e.g., optimization modeling, Six Sigma). Even the proposed perspective is not limited to analytical IT resources alone. Rather, this research has drawn upon an established body of the RBV literature on IT and the impact of IT, and formulated a view of SCA as a combination of IT-enabled resources, including IT assets, analytical methods, and evidence-based methodologies. Thus, managers are discouraged from taking the simplistic view that a single analytical IT or data management tool alone would create business value. Instead, they should consider a combination of various IT-enabled resources for data management, analytical and modeling methods, and fact-based methodologies. This can lead to a systematic investment in those SCA IT-enabled resources, resulting in competitive advantage and performance improvement. Specifically, each set of IT-enabled resources is found to be important for improving operational performance: DMR (data management resources) is posed to be the key building block of SCA; IPR (IT-based supply chain planning resources) is driving for greater planning satisfaction and enabling the adoption of PMR (performance management resources), which have been found to be important complementarities in the implementation of SCA in practice.

Finally, there is room for improvement of the research model. One potential improvement is to include additional latent variables or items in the research design. Our research model included three latent variables (DMR, IPR, PMR). Other firm resources or capabilities could be 
included in future research models. Other potential latent variables or items would be leadership, organizational structure, analytical skills, and partner support (Pfeffer and Sutton 2006, Dong et al. 2009, Davenport et al. 2010, Oliva and Watson 2011). For example, manufacturers' management leadership and culture could be good organizational resources for SCA. Manufacturers operate their supply chains with a large network of partners, who become the source of the data used for supply chain planning and performance management. Therefore, the partners' IT resources for data sharing could be considered in the future research design. Furthermore, the data were collected between 2007 and 2009 (Whybark et al. 2009). While we have no evidence to believe the relationships among those variables in the model have had significant changes in the last three or four years, the proposed model should be validated with more recent data in the future. Overall, the current research design and its findings offer vital information to better understand the role of business analytics for supply chain management and its impact on operational performance. 


\section{Appendix A: Distribution of industries and firm size}

(a) Firm size

\begin{tabular}{|c|c|c|}
\hline Size & Frequency & Percentage \\
\hline (1) $>=50$ employees & 116 & $21.6 \%$ \\
\hline (2) 51 - 250 employees & 206 & $38.3 \%$ \\
\hline (3) $>=251$ employees & 180 & $33.5 \%$ \\
\hline N/A & 35 & $6.5 \%$ \\
\hline Total & 537 & $100.0 \%$ \\
\hline
\end{tabular}

(b) Industry

\begin{tabular}{|c|c|c|c|c|c|}
\hline Industry & Freq. & Percent & Industry & Freq. & Percent \\
\hline Electronic and other Equipment & 104 & $19.4 \%$ & $\begin{array}{l}\text { Motor vehicles, trailers and } \\
\text { semi trailers }\end{array}$ & 15 & $2.8 \%$ \\
\hline $\begin{array}{l}\text { Industrial machines and computer } \\
\text { equipment }\end{array}$ & 74 & $13.8 \%$ & $\begin{array}{l}\text { Other manufactured transport } \\
\text { equipment }\end{array}$ & 11 & $2.0 \%$ \\
\hline Fabricated metal & 55 & $10.2 \%$ & $\begin{array}{l}\text { Apparel and Other finished } \\
\text { Products }\end{array}$ & 11 & $2.0 \%$ \\
\hline Food Products GMP & 37 & $6.9 \%$ & $\begin{array}{l}\text { Printing and Publishing and } \\
\text { Allied Industries }\end{array}$ & 10 & $1.8 \%$ \\
\hline Textile Mill Products & 32 & $6.0 \%$ & Paper and allied products & 10 & $1.8 \%$ \\
\hline $\begin{array}{l}\text { Stone clay glass and concrete } \\
\text { products }\end{array}$ & 26 & $4.8 \%$ & Miscellaneous Manufacturing & 98 & $18.2 \%$ \\
\hline Furniture and fixtures & 21 & $3.9 \%$ & Total & 537 & $100.0 \%$ \\
\hline Rubber and Plastic products & 18 & $3.4 \%$ & & & \\
\hline Chemical and allied products & 15 & $2.8 \%$ & & & \\
\hline
\end{tabular}




\section{Appendix B: Detailed information on constructs}

\begin{tabular}{|l|l|l|}
\hline Construct: DMR (Data management resources) & Mean & S.D \\
\hline $\begin{array}{l}\text { 1) Method of recording data: manually written or typed on paper files / manually } \\
\text { typed into computerized system / bar codes / automatic data capture using RFID, } \\
\text { etc. }\end{array}$ & 2.378 & 0.775 \\
2) The primary way of determining manufacturing data such as manufacturing batch \\
size: experience / statistical methods / mathematical optimization & 1.749 & 0.764 \\
3) Degree of investment in centralized data repository such as ERP. 1: not at all - 7: \\
to a great extent
\end{tabular}

\begin{tabular}{|l|l|l|}
\hline Construct: IPR (IT-based supply chain planning resources) & Mean & S.D \\
\hline 1) How is material planning (e.g., Material Requirement Planning, MRP) performed? & 3.182 & 1.402 \\
2) How is inventory control (e.g., Quantity/location accuracy) performed? & 3.264 & 1.302 \\
3) How is labor planning (e.g., Capacity Requirements Planning) performed? & 2.492 & 1.416 \\
4) How is shop floor control (e.g., Production Activity Control) performed? & 2.646 & 1.432 \\
5) How is cost planning performed? & 3.022 & 1.320 \\
0: no formal system / 1: manual / 2: desktop software / 3: custom software / 4: & & \\
commercial software / 5: modified commercial software & & \\
\hline
\end{tabular}

\begin{tabular}{|l|l|l|}
\hline Construct: PMR (Performance management resources) & Mean & S.D \\
\hline 1) Extent of invested resources in TQM & 4.587 & 1.695 \\
2) Extent of invested resources in Statistical Process Control & 3.842 & 1.802 \\
3) Extent of invested resources in Six Sigma & 2.927 & 1.995 \\
1: not at all - 7: to a great extent & & \\
\hline
\end{tabular}

\begin{tabular}{|l|l|l|}
\hline Construct: SAT (Supply chain planning satisfaction & Mean & S.D \\
\hline To what extent are you satisfied with your current: & & \\
1) Material Planning & 4.680 & 1.520 \\
2) Inventory Control & 4.791 & 1.538 \\
3) Labor Planning & 4.298 & 1.527 \\
4) Shop Floor Control & 4.501 & 1.510 \\
5) Cost Planning & 4.674 & 1.517 \\
1: very dissatisfied - 7: very satisfied & & \\
\hline
\end{tabular}

\begin{tabular}{|l|l|l|}
\hline Construct: SCP (SCM performance) & Mean & S.D \\
\hline Compare the performance with your major competitors & & \\
1) Order Fulfillment & 5.266 & 1.225 \\
2) Delivery As Promised & 5.264 & 1.182 \\
3) Delivery Flexibility & 5.356 & 1.145 \\
4) Flexibility to Change Output Volume & 5.117 & 1.212 \\
5) Flexibility to Change Product Mix & 5.091 & 1.257 \\
1: far worse - 7: far better & & \\
\hline
\end{tabular}




\section{References}

Acar, Y., Kadipasaoglu, S. \& Schipperijn, P., 2010. A decision support framework for global supply chain modelling: An assessment of the impact of demand, supply and lead-time uncertainties on performance. International Journal of Production Research, 48 (11), 3245-3268.

Armstrong, C. \& Shimzu, K., 2007. A review of approaches to empirical research on the resource-based view of the firm. Journal of Management, 33 (6), 959-986.

Barney, J., 1991. Firm resources and sustained competitive advantage. Journal of Management, 17 (1), 99-120.

Bendoly, E., 2003. Theory and support for process frameworks of knowledge discovery and data mining from erp systems. Information \& Management, 40, 639-647.

Benton, W. \& Maloni, M., 2005. The influence of power driven buyer/seller relationships on supply chain satisfaction. Journal of Operations Management, 23 (1), 1-22.

Bharadwaj, A., 2000. A resource-based perspective on information technology capability and firm performance: An empirical investigation. MIS Quarterly, 24, 169-196.

Blome, C., Schoenherr, T. \& Rexhausen, D., 2013. Antecedents and enablers of supply chain agility and its effect on performance: A dynamic capabilities perspective. International Journal of Production Research, 51 (4), 1295-1318.

Chae, B., Yen, H.J. \& Sheu, C., 2005. Information technology and supply chain collaboration: Moderating effects of existing relationships between partners, IEEE Transactions Engineering Management, 52 (4), 440-448.

Chellappa, R., Sambamurthy, V. \& Saraf, N., 2010. Competing in crowded markets: Multimarket contact and the nature of competition in the enterprise systems software industry. Information Systems Research 21 (3), 614-630.

Chin, W., 2010. How to write up and report pls analyses. In Vinzi, V. ed. Handbook of partial least squares. Berlin: Springer-Verlag, 655-690.

Clark, L., 2013. Tesco uses supply chain analytics to save $£ 100 \mathrm{~m}$ a year. http://www.computerweekly.com/news/2240182951/Tesco-uses-supply-chain-analyticsto-save-100m-a-year.

Davenport, T., Harris, J.G. \& Morison, R., 2010. Analytics at work: Smarter decisions, better results Boston, MA: Harvard Business Press.

Davenport, T. \& O'dwyer, J., 2011. Tap into the power of analytics. Supply Chain Quarterly, Fourth Quarter, 28-31.

Davenport, T.H. \& Harris, J.G., 2007. Competing on analytics: The new science of winning Boston: Harvard Business School Press.

Davis-Sramek, B., Germain, R. \& Iyer, K., 2010. Supply chain technology: The role of environment in predicting performance. Journal of the Academy of Marketing Science, 38, 42-55.

De Leeuw, S. \& Van Den Berg, J., 2011. Improving operational performance by influencing shop floor behavior via performance management practices. Journal of Operations Management, 29 (3), 224-235.

De Snoo, C., Wezel, W. \& Jorna, R., 2011. An empirical investigation of scheduling performance criteria. Journal of Operations Management, 29, 181-193.

Dehning, B., Richardson, V. \& Zmud, R., 2007. The financial performance effects of it-based supply chain management systems in manufacturing firms. Journal of Operations Management, 25, 806-824. 
Delen, D., Hardgrave, B. \& Sharda, R., 2007. Rfid for better supply chain management through enhanced information visibility. Production and Operations Management, 16 (5), 613624.

Delone, W. \& Mclean, E., 1992. Information systems success: The quest for the dependent variable. Information Systems Research, 3 (1), 60-95.

Demirkan, H. \& Delen, D., 2012. Leveraging the capabilities of service-oriented decision support systems: Putting analytics and big data in cloud. Decision Support Systems, 55 (1), 412-421.

Devaraj, S. \& Kohli, A., 2003. Performance impacts of information technology: Is actual usage the missing link? Management Science, 49 (3), 273-289.

Devaraj, S., Krajewski, L. \& Wei, J., 2007. Impact of ebusiness technologies on operational performance: The role of production information integration in the supply chain. Journal of Operations Management, 25, 1199-1216.

Dionne, L. \& Kempf, K., 2011. Data in production and supply chain planning. In Kempf, K. ed. Planning production and inventories in the extended enterprise. Springer, 167-184.

Dong, S., Xu, S. \& Zhu, K., 2009. Information technology in supply chains: The value of itenabled resources under competition. Information Systems Research, 20 (1), 18-32.

Economist, 2010. The data deluge. The Economist, (Feb 25).

Fairbank, J., Labianca, G., Steensma, H. \& Metters, R., 2006. Information processing design choices, strategy, and risk management performance. Journal of Management Information Systems, 23 (1), 293-319.

Flynn, B., Schroeder, R. \& Sakakibara, S., 1994. A framework for quality management research and an associated measurement instrument. Journal of Operations Management, 11, 339366.

Fornell, C. \& Larcker, D., 1981. Evaluating structural equation models with unobservable variables and measurement error. Journal of Marketing Research, 18 (1), 39-50.

Forslund, H. \& Jonsson, P., 2007. The impact of forecast information quality on supply chain performance. International Journal of Operations \& Production Management, 27, 90107.

Galbraith, J., 1974. Organization design: An information processing view. Interfaces, 4 (3), 2836.

Gefen, D., Ridgon, E. \& Straub, D., 2011. An update and extension to sem guidelines for administrative and social science research. MIS Quarterly, 35 (2), 3-16:A1-A7.

Gefen, D., Straub, D. \& Boudreau, M., 2000. Structural equation modeling and regression: Guidelines for research practice. Communications of AIS, 4 (7), 1-74.

Gustavsson, M. \& Wanstrom, C., 2009. Assessing information quality in manufacturing planning and control processes. International Journal of Quality \& Reliability Management, 26 (4), 325-340.

Hair, J., Ringle, C. \& Sarstedt, M., 2011. Pls-sem: Indeed a silver bullet. Journal of Marketing Theory and Practice, 19 (2), 139-151.

Hair, J., Sarstedt, M., Ringle, C. \& Mena, J., 2012. An assessment of the use of partial least squares structural equation modeling in marketing research. Journal of the Academy of Marketing Science, 40 (3), 414-433.

Handfield, R., 2006. Supply market intelligence: A managerial handbook for building sourcing strategies New York: Taylor \& Francis 
Handfield, R. \& Nichols, E., 2004. Key issues in global supply base management. Industrial Marketing Management, 33, 29-35.

Hendricks, K., Singhal, V. \& Stratman, J., 2007. The impact of enterprise systems on corporate performance: A study of erp, scm, and crm system implementation. Journal of Operations Management, 25, 65-82.

Holweg, M., 2007. The genealogy of lean production. Journal of Operations Management, 25, 420-437.

Houghton, R., El Sawy, O., Gray, P., Donegan, C. \& Joshi, A., 2004. Vigilant information systems for managing enterprises in dynamic supply chains: Realtime dashboards at western digital. MIS Quarterly Executive, 3 (1), 19-35.

Huner, K., Schierning, A., Otto, B. \& Osterle, H., 2011. Product data quality in supply chains: The case of beierdorf. Electronic Markets, 21, 141-154.

Jander, M., 2011. Supply chain analytics: New kid on it's block. Internet Evolution. http://www.internetevolution.com/author.asp?section_id=625\&doc_id=205911 Accessed on $4 / 21 / 2011$.

Jeffers, P., Muhanna, W. \& Nault, B., 2008. Information technology and process performance: An empirical investigation of the interaction between it and non-it resources. Decision Sciences, 39 (4), 703-735.

Kannan, V. \& Tan, K., 2005. Just in time, total quality management, and supply chain management: Understanding their linkages and impact on business performance. Omega, 33, 153-162.

Kaynak, H. \& Hartley, J., 2008. A replication and extension of quality management into the supply chain. Journal of Operations Management, 26, 468-489.

Kiron, D., Shockey, R., Kruschwitz, N., Finch, G. \& Haydock, M., 2011. Analytics: The widening divide. MIT Sloan Management Review, 53 (3), 1-22.

Kohli, R. \& Grover, V., 2008. Business value of it: An essay on expanding research directions to keep up with the times. Journal of Association for Information Systems, 9 (1), 23-39.

Kreipl, S. \& Pinedo, M., 2004. Planning and scheduling in supply chains: An overview of issues in practice. Production and Operations Management, 13 (1), 77-92.

Kusiak, A., 2006. Data mining: Manufacturing and service applications. International Journal of Production Research, 44 (18-19), 4175-4191.

Laframboise, K. \& Reyes, F., 2005. Gaining competitive advantage from integrating enterprise resource planning and total quality management. Journal of Supply Chain Management, 41 (3), 49-64.

Lavalle, S., Lesser, E., Shockey, R.H., M \& Kruschwitz, N., 2011. Big data, analytics and the path from insights to value. MIT Sloan Management Review, 52 (2), 21-32.

Liberatore, M. \& Luo, W., 2010. The analytics movement. Interfaces, 40 (4), 313-324.

Mackenzie, S., Podsakoff, P. \& Podsakoff, N., 2011. Construct measurement and validation procedures in mis and behavioral research: Integrating new and existing techniques. MIS Quarterly, 35 (2), 293-334.

Manyika, J., Chui, M., Brown, B., Bughin, J., Dobbs, R., Roxburgh, C. \& Byers, A., 2011. Big data: The next frontier for innovation, competition, and productivity. McKinsey Report.

Marchand, D., Kettinger, W. \& Rollins, J., 2000. Information orientation: People, technology and the bottom line. Sloan Management Review, 41 (4), 69-80. 
Martinez-Lorente, A., Sanchez-Rodriguez, C. \& Dewhurst, F., 2004. The effect of information technologies on tqm: An initial analysis. International Journal of Production Economics, 89, 77-93.

Merino-Díaz De Cerio, J., 2003. Quality management practices and operational performance: Empirical evidence for spanish industry. International Journal of Production Research, 41 (12), 2763-2786.

Mithas, S., Ramasubbu, N. \& Sambamurthy, V., 2011. How information management capability influences firm performance. MIS Quarterly, 35 (1), 237-256.

Nair, A., 2006. Meta-analysis of the relationship between quality management practices and firm performance-implications for quality management theory development. Journal of Operations Management, 24, 948-975.

Narasimhan, R. \& Schoenherr, T., 2012. The effects of integrated supply management practices and environmental management practices on relative competitive quality advantage. International Journal of Production Research, 50 (4), 1185-1201.

Nevo, S. \& Wade, M., 2010. The formation and value of it-enabled resources: Antecedents and consequences of synergistic relationships. MIS Quarterly, 34 (1), 163-183.

Nevo, S. \& Wade, M., 2011. Firm-level benefits of it-enabled resources: A conceptual extension and an empirical assessment. Journal of Strategic Information Systems, 20, 403-418.

Newbert, S., 2007. Empirical research on the resource-based view of the firm: An assessment and suggestions for future research. Strategic Management Journal, 28, 121-146.

Nunnally, J. \& Bernstein, I., 1994. Psychometric theory New York: McGraw-Hill.

O'dwyer, J. \& Renner, R., 2011. The promise of advanced supply chain analytics. Supply Chain Management Review, 15, 32-37.

Oliva, R. \& Watson, N., 2011. Cross functional alignment in supply chain planning: A case study of sales \& operations planning. Journal of Operations Management, 29 (5), 434448.

Olson, D.L., Chae, B. \& Sheu, C., 2013. Relative impact of different ERP forms on manufacturing organisations: An exploratory analysis of a global manufacturing survey. International Journal of Production Research, 51 (5), 1520-1534.

Penrose, E., 1959. The theory of the growth of the firm New York: Wiley.

Petter, S. \& Mclean, E., 2009. A meta-analytic assessment of the delone and mclean is success model: An examination of is success at the individual level. Information \& Management, 46, 159-166.

Pfeffer, J. \& Sutton, R., 2006. Evidence-based management. Harvard Business Review, 84 (1), 62-74.

Podsakoff, P.M., Mackenzie, S.B., Lee, J.-Y. \& Podsakoff, N.P., 2003. Common method biases in behavioral research: A critical review of the literature and recommended remedies. Journal of Applied Psychology, 88, 879-903.

Powell, T. \& Dent-Micallef, A., 1997. Information technology as competitive advantage: The role of human, business, and technology resources. Strategic Management Journal, 18 (5), 375-405.

Rungtusanatham, M., 2001. Beyond improved quality: The motivational effects of statistical process control. Journal of Operations Management, 19, 653-673.

Sas, 2012. Supply chain analytics: Beyond erp and scm: Www.Sas, C.

Scheuermann, L., Zhu, Z. \& Scheuermann, S., 1997. Tqm success efforts: Use more quantitative or qualitative tools? Industrial Management \& Data, 97 (7), 264-270. 
Schroeder, R., 2008. Six sigma: Definition and underlying theory. Journal of Operations Management, 26, 536-554.

Sellitto, C., Burgess, S. \& Hawking, P., 2007. Information quality attributes associated with rfidderived benefits in the retail supply chain. International Journal of Retail \& Distribution Management, 35 (1), 69-87.

Shah, R. \& Ward, P., 2003. Lean manufacturing: Context, practice bundles, and performance. Journal of Operations Management, 21, 129-149.

Shah, R. \& Ward, P., 2007. Defining and developing measures of lean production. Journal of Operations Management, 25 (4), 785-805.

Shapiro, J., 2000. Modeling the supply chain: Duxbury Applied.

Shapiro, J., 2010. Advanced analytics for sales \& operations planning. Analytics Magazine, MayJune, 20-26.

Singh, N., 2003. Emerging technologies to support supply chain management. Communications of the ACM, 46 (9), 243-247.

Stadtler, H., 2005. Supply chain management and advanced planning--basics, overview and challenges. European Journal of Operational Research, 163, 575-588.

Su, Y. \& Yang, C., 2010. Why are enterprise resource planning systems indispensable to supply chain management? European Journal of Operational Research, 203, 81-94.

Tippins, M. \& Sohi, R., 2003. It competency and firm performance: Is organizational learning a missing link? Strategic Management Journal, 24 (8), 745-761.

Trkman, P., Mccormack, K., De Oliveira, M. \& Ladeira, M., 2010. The impact of business analytics on supply chain performance. Decision Support Systems, 49 (3), 318-327.

Turban, E. \& Sepehri, M., 1986. Applications of decision support and expert systems in flexible manufacturing systems. Journal of Operations Management, 6 (3-4), 433-448.

Turban, E., Sharda, R., Delen, D. \& King, D., 2011. Business intelligence: A managerial approach, 2 ed. New York: Prentice Hall.

Viswanathan, N. \& Sadlovska, V., 2010. Supply chain intelligence: Adopt role-based operational business intelligence and improve visibility. Aberdeen Group.

Vollmann, T., Berry, W., Whybark, D. \& Jacobs, F., 2005. Manufacturing planning and control for supply chain management, 5th ed.: McGraw Hill.

Vosburg, J. \& Kumar, A., 2001. Managing dirty data in organizations using erp: Lessons from a case study. Industrial Management \& Data Systems, 101 (1), 21-31.

Wade, M. \& Hulland, J., 2004. The resource-based view and information systems research: Review, extension, and suggestions for future research. MIS Quarterly, 28 (1), 107-142.

Ward, P., Mccreery, J., Ritzman, L. \& Sharma, D., 2007. Competitive priorities in operations management. Decision Sciences, 29 (4), 1035-1046.

Wernerfelt, B., 1984. A resource-based view of the firm. Strategic Management Journal, 5 (2), 171-180.

Whybark, D., Wacker, J. \& Sheu, C., 2009. The evolution of an international academic manufacturing survey. Decision Line, May, 17-19.

Wixom, B. \& Todd, P., 2005. A theoretical integration of user satisfaction and technology acceptance. MIS Quarterly, 16 (1), 85-102.

Wu, F., Yeniyurt, S., Kim, D. \& Cavusgil, S., 2006. The impact of information technology on supply chain capabilities and firm performance: A resource-based view. Industrial Marketing Management, 35, 493-504. 
Yang, H., Choi, B., Park, H., Suh, M. \& Chae, B., 2007. Supply chain management six sigma: A management innovation methodology at the samsung group. Supply Chain Management: An International Journal, 12 (2), 88-95.

Yang, C., Wacker, J. \& Sheu, C., 2012. What makes outsourcing effective - A transaction cost economics analysis. International Journal of Production Research, 50 (16), 4462-4476.

$\mathrm{Zu}$, X., Fredendall, L. \& Douglas, T., 2008. The evolving theory of quality management: The role of six sigma. Journal of Operations Management, 26 (5), 630-650.
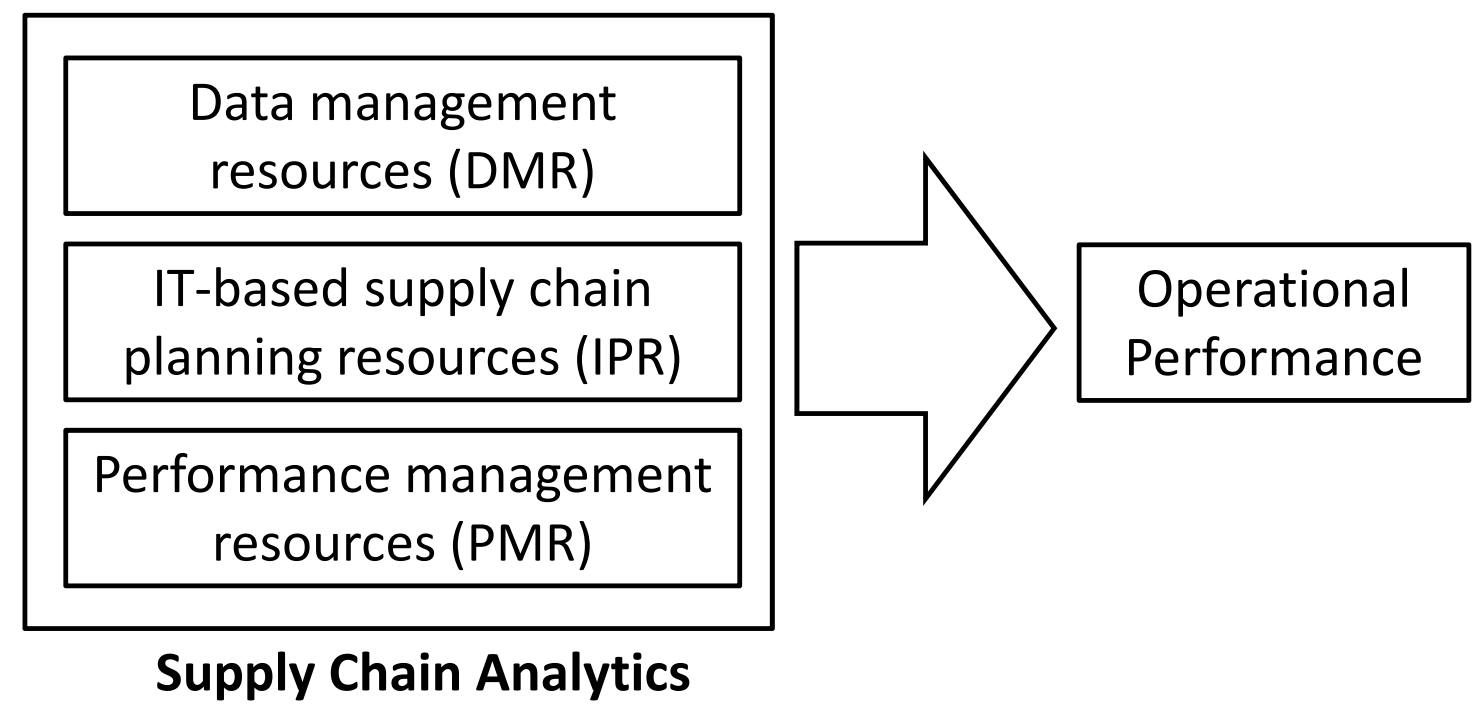

Figure 1. Conceptual model 


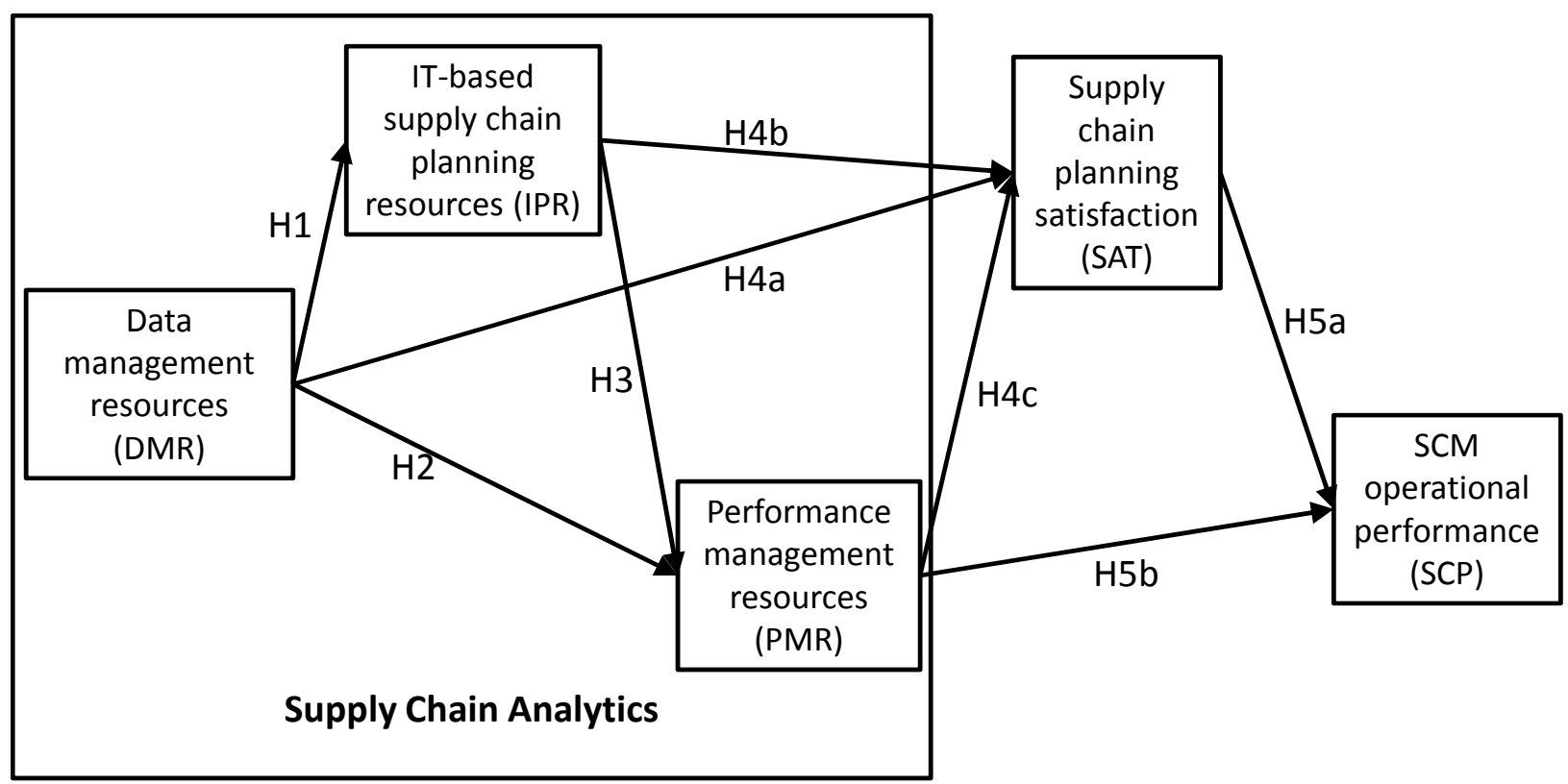

Figure 2. Research model

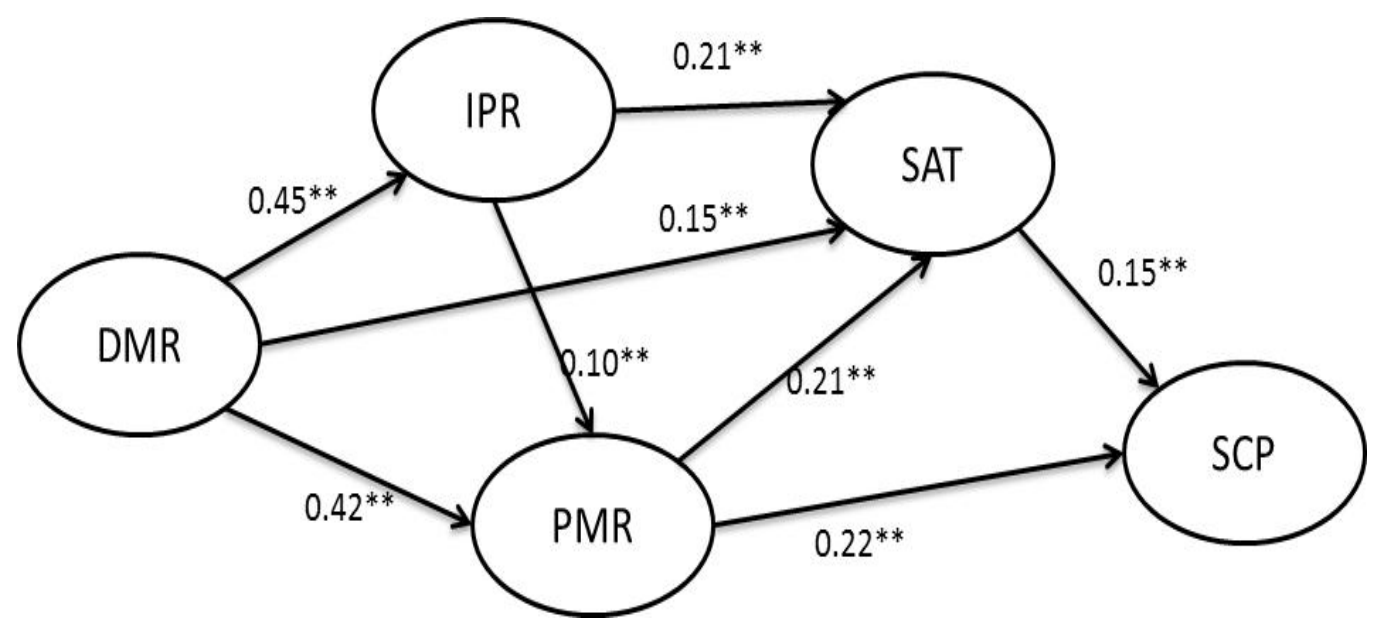

Note: ** significant at 0.01 level

Figure 3. PLS-SEM results 
Table 1. Composite reliability and average variances extracted (AVE)

\begin{tabular}{|r|c|c|c|c|c|c|c|}
\hline $\begin{array}{l}\text { Composite } \\
\text { Reliability }\end{array}$ & AVE & & DMR & IPR & \multicolumn{1}{c|}{ PMR } & SAT & \multicolumn{1}{c|}{ SCP } \\
\hline 0.742 & 0.491 & DMR & $\mathbf{0 . 7 0 1}$ & 0.438 & 0.462 & 0.328 & 0.054 \\
\hline 0.901 & 0.647 & IPR & 0.438 & $\mathbf{0 . 8 0 4}$ & 0.293 & 0.316 & 0.006 \\
\hline 0.809 & 0.586 & PMR & 0.462 & 0.293 & $\mathbf{0 . 7 6 6}$ & 0.321 & 0.271 \\
\hline 0.910 & 0.670 & SAT & 0.328 & 0.316 & 0.321 & $\mathbf{0 . 8 1 8}$ & 0.211 \\
\hline 0.902 & 0.649 & SCP & 0.054 & 0.006 & 0.271 & 0.211 & $\mathbf{0 . 8 0 6}$ \\
\hline \multicolumn{7}{r|}{} \\
\hline
\end{tabular}

Table 2. Loadings and cross-loadings

\begin{tabular}{|l|r|r|r|r|r|r|}
\hline \multicolumn{1}{|c|}{ Item } & DMR & IPR & PMR & SAT & SCP & P value \\
\hline DMR_1 & $\mathbf{0 . 7 6}$ & 0.06 & -0.05 & -0.01 & -0.04 & $<0.001$ \\
\hline DMR_2 & $\mathbf{0 . 7 2}$ & -0.08 & -0.15 & -0.02 & -0.03 & $<0.001$ \\
\hline DMR_3 & $\mathbf{0 . 6 2}$ & 0.02 & 0.23 & 0.04 & 0.09 & $<0.001$ \\
\hline IPR_1 & 0.02 & $\mathbf{0 . 8 2}$ & -0.03 & -0.09 & 0.03 & $<0.001$ \\
\hline IPR_2 & -0.03 & $\mathbf{0 . 8 3}$ & -0.01 & -0.07 & 0.05 & $<0.001$ \\
\hline IPR_3 & 0.03 & $\mathbf{0 . 7 9}$ & 0.02 & 0.10 & 0.00 & $<0.001$ \\
\hline IPR_4 & 0.05 & $\mathbf{0 . 7 8}$ & 0.00 & 0.02 & -0.03 & $<0.001$ \\
\hline IPR_5 & -0.07 & $\mathbf{0 . 8 0}$ & 0.03 & 0.05 & -0.05 & $<0.001$ \\
\hline PMR_1 & -0.18 & -0.05 & $\mathbf{0 . 7 4}$ & 0.11 & 0.08 & $<0.001$ \\
\hline PMR_2 & 0.06 & 0.00 & $\mathbf{0 . 8 2}$ & -0.03 & -0.05 & $<0.001$ \\
\hline PMR_3 & 0.11 & 0.05 & $\mathbf{0 . 7 3}$ & -0.07 & -0.02 & $<0.001$ \\
\hline SAT_1 & 0.01 & 0.07 & -0.07 & $\mathbf{0 . 8 2}$ & 0.03 & $<0.001$ \\
\hline SAT_2 & -0.04 & 0.07 & -0.07 & $\mathbf{0 . 8 1}$ & 0.06 & $<0.001$ \\
\hline SAT_3 & 0.04 & -0.08 & -0.03 & $\mathbf{0 . 8 4}$ & -0.01 & $<0.001$ \\
\hline SAT_4 & 0.03 & -0.03 & 0.04 & $\mathbf{0 . 8 2}$ & -0.05 & $<0.001$ \\
\hline SAT_5 & -0.05 & -0.03 & 0.14 & $\mathbf{0 . 8 0}$ & -0.03 & $<0.001$ \\
\hline SCP_1 & 0.07 & -0.07 & 0.01 & 0.04 & $\mathbf{0 . 8 1}$ & $<0.001$ \\
\hline SCP_2 & 0.04 & -0.06 & -0.03 & 0.07 & $\mathbf{0 . 7 8}$ & $<0.001$ \\
\hline SCP_3 & -0.03 & -0.04 & -0.05 & -0.01 & $\mathbf{0 . 8 5}$ & $<0.001$ \\
\hline SCP_4 & -0.04 & 0.08 & 0.07 & -0.05 & $\mathbf{0 . 8 3}$ & $<0.001$ \\
\hline SCP_5 & -0.04 & 0.09 & 0.00 & -0.05 & $\mathbf{0 . 7 6}$ & $<0.001$ \\
\hline Note: P values $<0.05$ are desirable for reflective indicators. & \\
\hline & & & & & & \\
\hline
\end{tabular}


Table 3. Summary of hypotheses and results

\begin{tabular}{|l|l|l|}
\hline $\mathrm{H} 1$ & DMR $\rightarrow$ IPR & Supported \\
\hline $\mathrm{H} 2$ & DMR $\rightarrow$ PMR & Supported \\
\hline $\mathrm{H} 3$ & IPR $\rightarrow$ PMR & Supported \\
\hline $\mathrm{H} 4 \mathrm{a}$ & DMR $\rightarrow$ SAT & Supported \\
\hline $\mathrm{H} 4 \mathrm{~b}$ & IPR $\rightarrow$ SAT & Supported \\
\hline $\mathrm{H} 4 \mathrm{c}$ & PMR $\rightarrow$ SAT & Supported \\
\hline $\mathrm{H} 5 \mathrm{a}$ & SAT $\rightarrow$ SCP & Supported \\
\hline H5b & PMR $\rightarrow$ SCP & Supported \\
\hline
\end{tabular}

Table 4. P values for correlations of latent variables

\begin{tabular}{|l|l|l|l|l|l|}
\hline & DMR & IPR & PMR & SAT & SCP \\
\hline DMR & 1.000 & $<0.001$ & $<0.001$ & $<0.001$ & $\mathbf{0 . 2 0 9}$ \\
\hline IPR & $<0.001$ & 1.000 & $<0.001$ & $<0.001$ & $\mathbf{0 . 8 8 3}$ \\
\hline PMR & $<0.001$ & $<0.001$ & 1.000 & $<0.001$ & $<0.001$ \\
\hline SAT & $<0.001$ & $<0.001$ & $<0.001$ & 1.000 & $<0.001$ \\
\hline SCP & 0.209 & 0.883 & $<0.001$ & $<0.001$ & 1.000 \\
\hline
\end{tabular}

